\title{
Supporting Coastal Resiliency by Investigating Tidal Reach and Inter-Connected Factors in Coastal Georgia
}

\author{
Shawn E. Rosenquist ${ }^{1}$ and Christopher J. Hintz ${ }^{2}$
}

AUTHORS: ${ }^{1}$ Instructor, Savannah State University, 3219 College St., Savannah, GA 31404, USA. ${ }^{2}$ Professor, Savannah State University, 3219 College St., Savannah, GA 31404, USA.

\begin{abstract}
Increasing our understanding of the tidal dynamics, the extent of tidal reach, and storm surge impacts on near-coastal areas of Georgia and South Carolina rivers is a significant research opportunity. It has the potential to yield benefits to sustainable planning, ecosystem protection, and risk management for regulators and state agencies, local municipalities, coastal residents, and other regional stakeholders. This study leveraged existing United States Geological Survey (USGS) water level data for the Savannah River, added additional water level gauges in key areas for less than one year, and analyzed these combined large data sets with modified wavelet analysis and Fourier analysis. One significant outcome of the research included confirmation of river mile 45, historically referred to as Ebenezer Landing, as the head of tide. We also provide information on the dynamics of wave propagation through the near-coastal area of the Savannah River, give indication of critical areas of concern for flooding resulting from interactions between the interconnected factors affecting elevated upstream flows and storm tides, and discuss relevance of study results for various stakeholders.
\end{abstract}

\section{INTRODUCTION}

The impetus for this research arose from a data gap regarding tidal reach in Georgia's major river systems. The Georgia Department of Natural Resources (GADNR) has already identified this need to determine the reach of tide. This need extends to the five major river systems in Georgia and is a high priority from the Protection of Tidewaters Act (O.C.G.A. 52-1-1 et seq.). In addition, the Georgia Environmental Protection Division (GAEPD) could utilize further information on the boundary location and conditional interactions between tidal and river-influenced hydrology to inform water quality models.

Improved understanding of the interaction between water levels in the Savannah River, tidal conditions, storm surge conditions, winds, and local rainfall could lead to improvements in understanding the local estuarine and near-coastal river hydrology. This, in turn, could lead to improvements in predictive modeling for regulation, environmental protection, and emergency preparedness for local and regional state government agencies.

While the application of this project beyond our community has broad relevance for many end users, it also has direct relevance for preparation, response, and mitigation of future coastal hazards from tropical cyclones and meteotsunamis. Flooding during hurricanes and tropical storms is not limited to the immediate coastal area but could extend well upriver due to interactions between abnormally high estuary water levels caused by storm surges and/or synergies of tidal forcing during spring tides. Higher rainfall intensity storms such as Hurricane Harvey (2017) and Hurricane Florence (2018) are setting new precedents for inland flooding impacts. It may become increasingly critical to evacuate low-lying areas 10-20 miles inland and near rivers. Moreover, while the spatial relationships of peak rainfall flooding, coastal storm surges, and estuary tidal fluctuations are important, the timing of these factors may also be critical to the prediction of a combined maximum local impact. These local combined impact predictions are potentially most critical for emergency management agencies to consider when organizing resources in preparation of these storm events and may occur outside of the predicted peak impact for storm surge or river stage.

Thus, another key deliverable of this project will be the identification of scenarios and specific locations where coalescing factors may cause upriver flooding not currently predicted by storm surge inundation models. Recent larger storms that impacted Savannah, Georgia, such as Matthew (2016) and Irma (2017) possessing differing approach vectors, wind fields, storm surge prediction, and highly-localized 
coastal inland flooding are creating a more complex scenario for evacuation versus shelter-in-place decisions. Further, efficient timing of evacuations must balance the necessary time for populations to prepare and travel away from the coast but attempt to avoid gridlock with larger areas and populations involved. Current storm surge inundation models and predictions from the Sea, Lake, and Overland Surges from Hurricanes (SLOSH) model do not incorporate river level or inland rainfall into risk assessments and inundation maps (NHC, "SLOSH"). Development and other human impacts also play a role. For the Savannah River in particular, recent work on the Savannah Harbor Expansion Project (SHEP) is making significant alterations to river bathymetry, which likely impacts upstream tides and storm surge extents.

\section{PROJECT DESCRIPTION}

\section{NEAR-COASTAL HYDROLOGY}

Near-coastal river hydrology is complex, involving multiple interconnecting tributaries and distributaries. According to Wolanski et al. (2013), "An estuary is never at steady state." Like rivers, estuaries can be responsive to precipitation, and water levels can vary greatly due to upstream flow. This flow can also have impacts on salinity and water quality. Beyond rainfall, a regulated river such as the Savannah can experience unusual changes in water flow in the estuary due to releases from upstream reservoirs. Of course, near-coastal areas are also impacted by downstream tides. Further, tides have multiple predictive drivers, primarily lunar and solar gravitational forcings, but also less predictive, more stochastic transient influences related to weather, wind speed, and wind direction.

These systems are also subject to alterations based on anthropogenic activities. In the Savannah River, historic modifications to facilitate navigation on the river have shortened and deepened the channel. According to Hale and Jackson (2003), the practice of cutting off oxbows in the river removed 26.5 miles of the lower Savannah River. Channel maintenance kept the river at a minimum of 9 feet deep and 90 feet wide throughout the lower basin, much of which occurred in areas that are not naturally that shape. Dredging and channeling activities, among other modifications, can impact the relative "age" of the estuary and the way it behaves in regard to the interaction of tide and river stage (Wolanski et al., 2013). In a critically important study to this work, Sassi and Hoitink (2013) indicate that the impact of upstream tidal forces on stage in the near-coastal area depends on bottom friction and upstream discharge. These modifications can affect the timing and magnitude of both of these elements. Dredging can reduce friction, and shortening can reduce the opportunity for longitudinal dispersion of precipitationdriven waveforms.
While understanding near-coastal hydrology may be difficult, it is also critically important. Wei et al. (2013) details the various reasons why accurate prediction of hydrology in this portion of rivers is so necessary, including "monitoring pollutant load, calculating sediment transport, controlling flood and drought, determining environmental flows, power generation, reservoir operation, and agricultural irrigation, as well as water supply to industry and households." Nearcoastal areas are heavily subjected to the effects of tropical cyclones, face heavy pressure from development and industrial water uses, and are an accumulation point for upstream pollution that may have increased residence time and/or deposit in near-coastal areas.

\section{TIME SERIES ANALYSIS AND HYDROLOGIC MODELING}

River hydrology, particularly in near-coastal areas, has been studied with time-series methods in many instances. Much of the foundational work with wavelet analysis involving river flows and tides was done by Jay and Flinchem $(1997,2000)$ in the Columbia River Estuary. Wavelet analysis involves the use of a dynamic "mother wavelet" in numerical analysis to deconstruct and analyze complex time-series data. Jay and Flinchem (1997, 2000) showed continuous wavelet transforms to be a very useful tool in describing the interactive behavior of tides with upstream flows. Prior to this, much of the work done in this area had utilized harmonic analysis (Matte et al., 2013) and Fourier analysis. These methods suffered from limitations that wavelet analysis can help move past, particularly the analysis of quasi-periodic phenomena. The wavelet methods were further developed in Jay et al. (2015) to include the effects of additional complexities, including floodplain wetlands. A review by Hoitink and Jay (2016) includes work done using a variety of methods, including those described above, in many coastal river systems around the world, such as the Columbia, the Amazon, and the Yangtze. Among other things, it describes the existence of fortnightly tides extending into upstream reaches explained through these methods. Sassi and Hoitink (2013) used wavelet analysis with a distributed network of pressure sensors to investigate the effect of tidal and upstream stage on near-coastal water levels through an estimate of sub-tidal friction. Wei et al. (2013) used wavelet analysis and artificial neural network modeling to predict river discharge in a subsequent year. Moftakhari et al. (2013) estimated Sacramento River discharge with wavelet data and regression and were able to hindcast annual freshwater discharge to the estuary. Moftakhari et al. (2016) used stage data over approximately $200 \mathrm{~km}$ of the lower Columbia and Frasier Rivers, along with wavelet analysis and then regression to determine the relationship between river discharge and tidal factors. Then they used this relationship to estimate discharge where tidal information is known but discharge is absent. Kisi (2011) utilized a combination of 


\section{Supporting Coastal Resiliency by Investigating Tidal Reach and Inter-Connected Factors}

wavelet analysis and regression to forecast daily river stage in the Schuylkill River. The study also indicated that regression analysis performed in a superior way to artificial neural networks for this system.

The analysis presented in this work shares many characteristics with the prior wavelet work described. However, it is done on a new system, the Savannah River, and in the context of a major, discrete, and anthropogenic impact: harbor deepening. While previous research focused on characterizing the waveforms, the research presented here focuses on using these techniques to identify a critical location within the estuary (i.e., head of tide, used in environmental protection, legislative action, and flooding hazard identification). Specifically, this approach uses higher spatial density of data collection and incorporates multiple complementary analyses to achieve the research objective.

The EDFC hydrodynamic model used in preparation for the Savannah Harbor Expansion Project covered the same area as this study, including the use of water level data from river mile 45 (RM45) near the mouth of Ebenezer Creek. It collected data as far upriver as Clyo, Georgia, at RM61 and downstream to the mouth of the river. This hydrodynamic modeling effort initially overestimated the tidal range at that location relative to observed data (approximately 0.5 $\mathrm{ft}$ of tidal range), before adding marsh areas and bottom roughness to the model to compensate (USACE, 2006). The same study described the Savannah River estuary system as very complex structurally and as a mixture of standing and progressive wave models, with the potential for multiple velocity peaks within a tidal cycle.

Mendelsohn et al. (1999) describes the Savannah as being a partially mixed estuary, but at the low end, indicating that river flows have a significant effect relative to tides. In contrast to these previous methods, tidal prediction has historically been calculated using Fourier analysis identifying scores to hundreds of harmonics that influence timing and amplitude of these low-frequency waves (Knauss, 1997). The key factor that separates these predictive models is regular, physically predictable driving forces versus stochastic events that are generally predictable but transient and difficult to couple with currently available models covering different regions of the estuary and lower reaches of the river.

Critical to all of these models and predictions is analysis of very long time-series data. While identification of transients and the impact of events like rainfall flooding, storm surges, and syzygy tidal events (i.e., king tides) is critical to future prediction, coastal resiliency, emergency management, and sustainable land-use development, fully understanding the "normal" or "baseline" responses within the highly dynamic and interconnected system in our estuary is paramount so that the transients can be identified distinctly beyond the normal conditions. However, changes to the system including the SHEP now limit the use of long-established historical river-gauge data. The impacts of these changes are being observed immediately, and the lack of predictive knowledge associated in how the river system behaves reduces our coastal resiliency and disaster preparation. Alternatively, the installation of multiple temporary river stage gauges provides additional concurrent data for analysis. Although these data are fundamentally different, they provide insights into both normal and transient behavior within the river basin.

\section{HEAD OF TIDE}

The Protection of Tidewaters Act (2010) stipulates that the state has ownership of waters that are "affected by the tide, where the tide rises and falls." This has been further defined by GADNR as the upstream extent of the river where the tidal range is at least $0.2 \mathrm{ft}$. We refer here to this definition for the term head of tide. While this legislation has existed for almost a decade, GADNR is still in need of data to verify the correct location for head of tide by this definition for the five major river systems in Georgia. This information is imperative for the mission of GADNR to implement this law. Historic reference placed the head of tide at or around the mouth of Ebenezer Creek at RM45 (USACE, 1994; USDOC, 1965). The USACE (1994) document references average tidal ranges of $6.8 \mathrm{ft}$ at the mouth of the river and $7.9 \mathrm{ft}$ at the upper limit of the harbor.

\section{HYDROLOGY AND COASTAL RESILIENCY}

Flooding associated with tropical cyclones is a major threat to life and property in coastal areas of the United States. Tropical cyclones can create flooding through torrential rains, as well as by pushing ocean water toward the shore through storm surges. Thus, in areas further upstream where these impacts are known to be more significant, there may be a potential for water levels that are higher than SLOSH alone might predict if a storm surge were to occur with an already high river level or be accompanied by significant upstream rainfall.

In recent years, storms such as Harvey (2017) in Texas and Florence (2018) in the Carolinas have challenged the conventional wisdom of the impacts of tropical storms being strongly correlated to their wind speeds. While Harvey did make landfall as a major hurricane, it quickly weakened and spent much of its time impacting near-coastal areas of Texas with torrential rains as a tropical storm. Florence, which made landfall as a category 1 hurricane, nevertheless caused significant near-coastal impacts due to precipitation-driven flooding. This type of storm could potentially have flooding impacts in near-coastal rivers that are not well captured by either precipitation-driven river-level modeling or coastal storm surge inundation modeling alone. 


\section{METHODS}

\section{STUDY AREA AND DATA COLLECTION}

The primary focus of this study was the area between the extent of the SLOSH model upriver past historically placed head of tide (USDOC, 1965; USCOE, 1994). This was roughly between RM27 and RM51. The larger area of study, included to investigate forcing from upstream flows and tidal range, was from RM1, the Fort Pulaski NOAA gauge, to RM61, the Clyo, Georgia, USGS gauge. The primary focus area included 6 temporary gauge stations set up through this study and 3 USGS gauges (Figure 1; Table 1). The larger area includes two additional USGS gauges at RM61 and RM1 (not pictured). The gauge at RM51 was originally located at RM31 but was moved to RM1 midway through the study to extend coverage. Neither RM31 nor RM51 proved to add significant additional information to the study and are not included in the analysis.

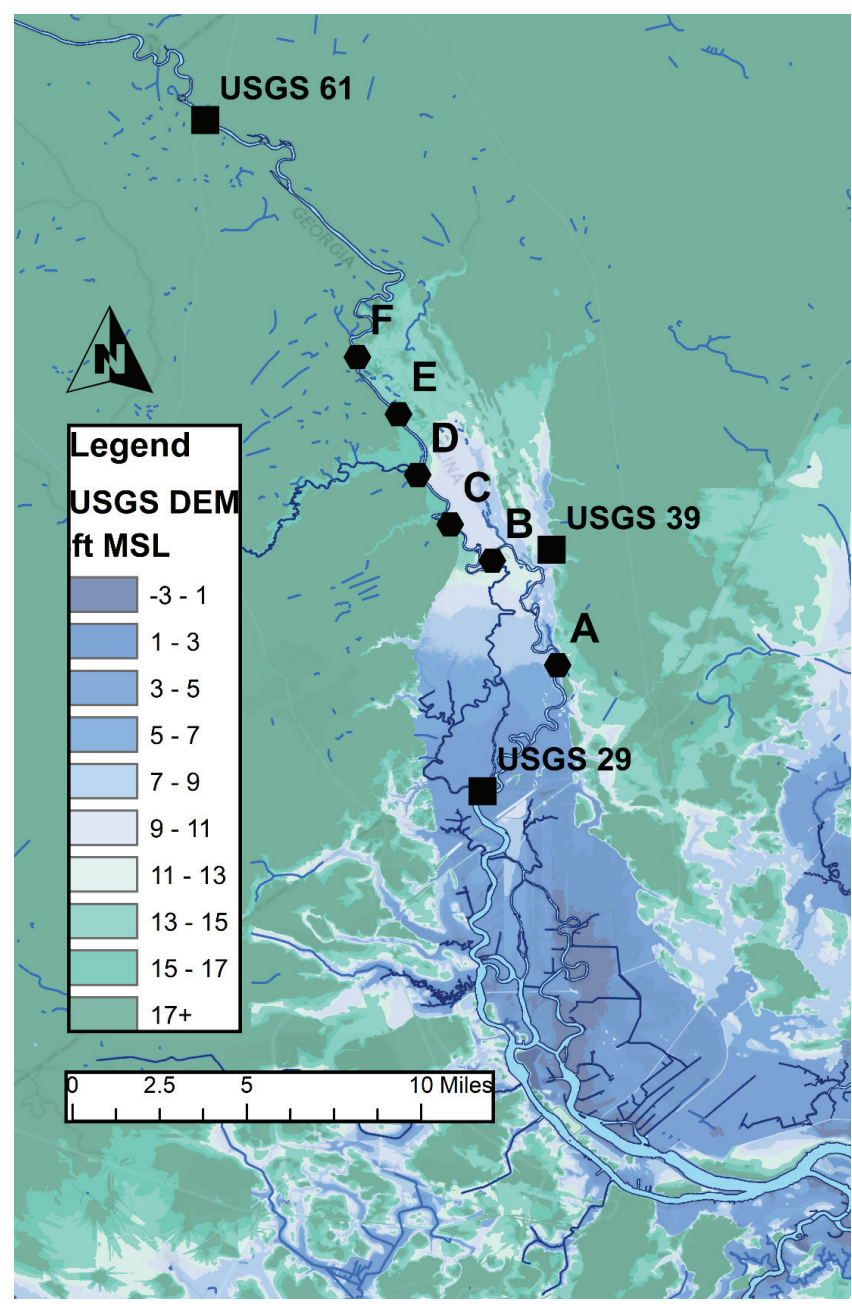

Figure 1. Map of the study area along the Savannah River north of Savannah, GA. Hexagons indicate location of temporary river gauge stations, squares indicate locations of long-term USGS river gauge stations between I-95 bridge and Clyo, GA. Area elevation is provided based on USGS DEM data, blue shades indicate areas potentially prone to flooding from storm surge or rainfall inundation flood events.
Table 1. Temporary station locations A-F along the Savannah River and long-term USGS river gauges locations within and near the study area.

\begin{tabular}{lccc}
\hline Site & RM & Latitude $\left(^{\circ}\right)$ & Longitude $\left(^{\circ}\right)$ \\
\hline $\mathrm{A}$ & 35 & 32.300738 & -81.122606 \\
$\mathrm{~B}$ & 41 & 32.346523 & -81.148278 \\
$\mathrm{C}$ & 43 & 32.361605 & -81.167482 \\
$\mathrm{D}$ & 45 & 32.380207 & -81.181679 \\
$\mathrm{E}$ & 48 & 32.420225 & -81.202193 \\
$\mathrm{~F}$ & 51 & 32.447231 & -81.206815 \\
& & & \\
USGS 02198840 & 28 & 32.235560 & -81.151390 \\
I-95 Bridge & & & \\
USGS 02198810 & 39 & 32.249167 & -81.153611 \\
Abercorn Cr. & & & \\
USGS 02198500 & 61 & 32.528056 & -81.268889 \\
Clyo, GA & & &
\end{tabular}

\section{WATER LEVEL LOGGER STATIONS}

Each temporary station consisted of a $30-\mathrm{ft}$ range $\mathrm{HOBO}$ water level logger (Onset Computer Corporation, Cape Cod, Massachusetts) suspended within a 6 to $10-\mathrm{ft}$ section of 3 -inch polyvinyl chloride pipe that served as a stilling well. The water level loggers were set to collect temperature and absolute pressure at 15-minute intervals continuously, synchronized to the hour, half-hour, and quarter-hour. The water level loggers were suspended in the pipe with stainless steel cable. The pipe sections were attached securely with twisted metal wire to sturdy structures such as relict wing dams, trees, or in a few cases steel posts driven deep into the riverbed. None of these temporary stilling wells gave any evidence of having measurably moved during the study period.

\section{DATA POST-PROCESSING}

As the water level loggers measure absolute pressure and not water level directly, it was necessary to perform a correction to the data to account for atmospheric pressure changes. Atmospheric pressure data were collected from the RM29 USGS gauge and applied to all of the temporary stations. Temperature data from the stations were also used for the correction, and an assumption of $0 \%$ salinity was used based on evidence from the RM27 USGS station claiming that salinity did not extend that far upstream. This was later verified during two station maintenance trips where independent Conductivity-Temperature-Depth readings (YSI Castaway CTD) of the river column adjacent to each station confirmed $<0.2 \%$ salinity. Temperature and salinity were used to determine water density in the calculation of water level.

Some additional data correction steps were necessary before the waveform matching could be completed. In 


\section{Supporting Coastal Resiliency by Investigating Tidal Reach and Inter-Connected Factors}

several instances there were sections of missing or lowquality data on the 15-minute intervals that caused problems in the waveform matching. Two different methods were used to account for missing data. The first method, when missing data were of short duration (less than 3 hours), was to interpolate between the existing data to fill in the gaps. The second method, for areas of longer duration, was to exclude this section of the data from analysis by creating 0 values that would not create matches. This only occurred at the RM45 temporary station due to movement of the water level logger on the cable out of the stilling well resulting in low-quality data. The stilling well was not observed to have moved. This movement is thought to be caused either by turbulent water at high flows or by tampering, and occurred between $4 / 29 / 18$ and $5 / 18 / 18$. One additional correction was made to data from the RM35 station. It was discovered after approximately 1 month of deployment that the tidal range was extended below the level of the water level logger for approximately 2 hours on certain days. This was corrected by moving the logger down by exactly $1 \mathrm{ft}$ at 10:00 on 3/29/2018 and adding one foot to the previous data. To manage the low-quality data that occurred when the logger was out of the water, it was discovered that during tidal minimum periods that were not out of the water, the data exhibited a consistent second derivative. This value was used to estimate these sections of data based on adjacent data.

\section{FOURIER ANALYSIS}

Post-processed data, with atmospheric correction and anomalous data removed or corrected, were analyzed using the fast Fourier transform (FFT) algorithm in MATLAB ${ }^{\circ}$ (Mathworks ${ }^{\circ}$, Natick, Massachusetts). Dominant spectral frequencies produced by the FFT were compared to wellestablished tidal harmonic periods to assess the influence of tidal forcings at each individual station. In particular, the 12.42-h period associated with the principal lunar semidiurnal $\left(\mathrm{M}_{2}\right)$ harmonic component was used in the Savannah River system to identify significant tidal influence at each river gauge station. An artifact of limited data $(<$ 365 days) and FFT analysis offers insufficient precision in analyzing significant frequencies identified by the technique. For example, a 100-day, 15-min sampling produced spectral precision of $\sim 0.4 \mathrm{~h}$ ( $2.4 \mathrm{~min}$ ) while a 250 -day, 15 -min sampling produced spectral precision of $\sim 0.2 \mathrm{~h}(1.2 \mathrm{~min})$. Further, specific spectral energy is often split between two adjacent frequencies that are very close to the true harmonic period, but which were not precisely binned into the physically defined period. Thus, our analysis extended the M2 harmonic period identification from $12.41-12.43 \mathrm{~h}$ to account for these data and analysis limitations. Lastly, spectral peaks are only identified as significant if their amplitude was 3 standard deviation above the variability produced by all frequencies. Additional refinement could improve this approach to
Fourier analysis, but that was beyond the scope of this initial assessment of the rapid, multiple, temporary river gauge analysis technique.

\section{WAVEFORM MATCHING}

The term waveform matching is used here instead of wavelet analysis because there are key differences between what is done here and what is normally meant by wavelet analysis. Wavelet analysis has been well described elsewhere and will not be described completely here, but some aspects of differences will be highlighted. For instance, while this analysis and wavelet analysis convolve functions or sets of functions through a time series to describe and deconstruct it into components, traditional wavelets are meant to integrate to zero (Vidakovic and Mueller, 1994), while the waveforms used in this analysis do not. Also, while wavelet analysis typically produces a matrix of values representing amplitude of periodic or quasi-periodic phenomena in the data for various regions of time and frequency in a generalized way, this method parameterizes each waveform in the data, even if it is the only one of a particular frequency and amplitude, at which point the method generalizes those matches. It is then possible to extract the matched parameters of each individual waveform if desired. This is the case for both the tide-based waveforms and the upstream discharge-based waveforms. While we will leave it to others to decide if the methods used here qualify as wavelet analysis, the method used is described in more detail as follows.

The waveform matching used in this study was based largely on the method originally developed for Rosenquist et al. (2010). Like the previous method, half-sine waveforms of a wide variety of wave heights and wave periods are

$$
H=\cos \left[\left(\frac{t p-t}{w}\right) \pi\right] a+T S_{k}-a
$$

individually superimposed on the time series at every possible point, and a quality of fit parameter is calculated for each potential match. Equation (1) is used to calculate the height of the superimposed wave at each point, compare it to the actual wave height, and then calculate a fit quality parameter (Figure 2). A large dataset of potential fits is thereby generated for various combinations of wave heights and periods over the entire data series. Then the large resulting dataset of potential fits is mined for the best quality fit for each portion of the data.

where:

- $H$ is waveform height in feet, so for a tide-based wave this would be the difference in stage from low to high tide,

- $T S_{k}$ is the actual river stage at $t_{p}$, 


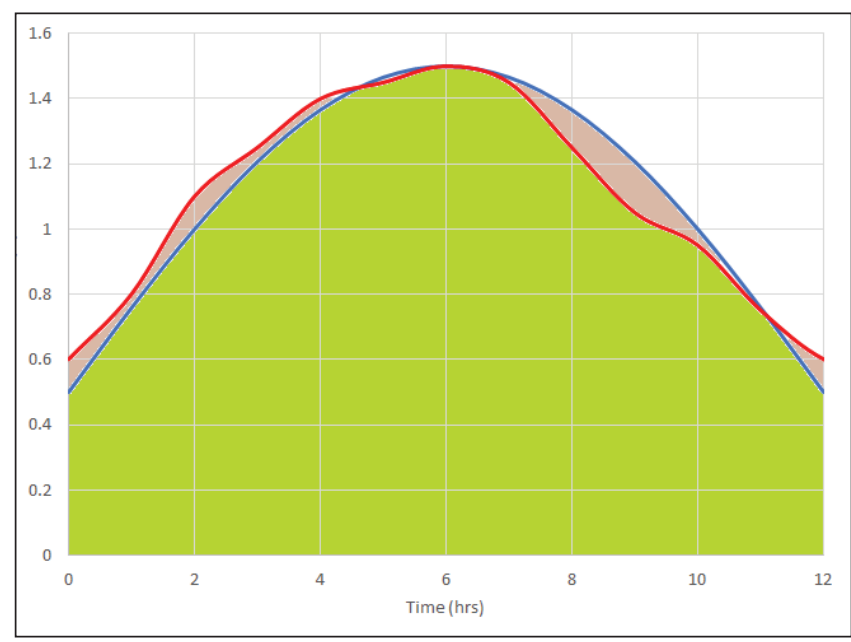

Figure 2. The blue line represents the test waveform while the red line represents the actual time-series data. The green area represents fit, while the tan area represents misfit.

- $w$ is the current wave period being tested for fit,

- $a$ is the current wave height being measured for fit,

- $t_{p}$ is the time in the time series representing the peak of the current waveform being evaluated,

- and $t$ is the measurement location in the current waveform being tested.

This method differs from the previous one based on the inclusion of the last two terms of Equation (1), which bind the peak waveform being tested to the current value of the time series being tested, instead of the previous method that bound the base of the waveform to zero. This is a distinct advantage over the previous method because it allows for more accurate evaluation of waveforms whose minimum values are not near zero. The determination of fit quality (Figure 2), which for this study was based on the ratio of misfit area to fit area, is also different from the original method, which was based on the ratio of fit to misfit. In the current method, a perfect fit would be zero, and fits are only accepted as accurately representing a waveform up to a certain level of misfit. Only fit quality values lower than 0.5 are recorded to prevent extremely long computer run times on low-quality data, as even some of the values below 0.5 are eliminated later in post-processing.

Both methods then select the best quality fit in the resulting dataset and eliminate that section of the time series from further selection. This process is continued until the entire dataset is eliminated or until no more matches of a certain quality can be found. Deconstruction of the time series into various signals is done by running the method with different sets of wavelengths so that both tidal and river waveforms can be found simultaneously. The first run is done with wavelengths of $6 \mathrm{hrs}$ to $24 \mathrm{hrs}$ for tide-based waves from downstream and the second set from $48 \mathrm{hrs}$ to $1,680 \mathrm{hrs}$ for precipitation or dam discharge-based waves from upstream. Downstream stage can be influenced by factors other than precipitation, such as the discrete high-volume releases in the Thurmond Dam at approximately RM215.

In the process of selecting the waveform matches the method also records the following for each match:

1. Match quality (misfit/fit, $0-0.5$ )

2. Match wave period

3. Match wave height

4. Time of peak

5. Actual stage at the match peak

6. Actual stage at the waveform minimums

The following additional parameters can then be calculated or searched for each match:

1. Actual height of rising limb

2. Actual height of falling limb

3. Actual averaged wave height (average of rising and falling limb heights)

4. RM61 stage at peak time

5. Most recent RM1 wave height

6. Time-matched wind speed/direction at NOAA Fripp Island Buoy

Determining the head of tide with waveform matching involved considering the distribution of waveforms found at each location and some attempt at interpolation between river miles and interpretation of the variation at each location. Boxplots are used to compare these distributions to the established criteria of $0.2 \mathrm{ft}$ to define head of tide. Interpolation methods assume linearity between adjacent river miles and included explanatory factors such as upstream flow and tidal range.

\section{POST-ANALYSIS QUALITY ASSESSMENT}

To assess the quality and interpretation of the Fourier analysis, an alternative, simple low-pass filter was applied to the corrected river gauge data as a moving 24 -h average. This 24 -h average with a $0.2 \mathrm{ft}$ "minimum tidal height" was compared to the unprocessed river gauge data. If the river gauge data exceeded the moving average with a $0.2-\mathrm{ft}$ head of tide criterion, this was an indication of tidal influence at the station.

A second quality assessment was the reconstruction of the single significant tidal harmonic identified by the Fourier analysis and compared the amplitude of this isolated waveform to the $0.2-\mathrm{ft}$ wave height head of tide criterion. If the wave amplitude exceeded the head of tide criterion, this also indicated significant tidal influence at the station. 


\section{Supporting Coastal Resiliency by Investigating Tidal Reach and Inter-Connected Factors}

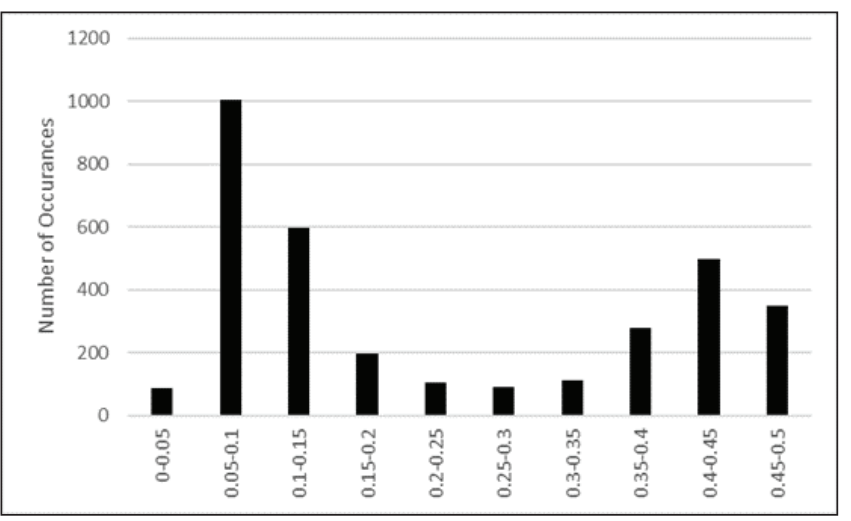

Figure 3. Histogram of waveform match (misfit/fit) quality parameters for all the matched waveforms. The minimum observed between the bimodal distribution of fits demonstrates two normal distributions of the analysis results, the lower peak representing higher-quality waveform matches. Thus, the 0.33 ratio at the minimum was identified as the maximum acceptable waveform match and higher values were omitted.

To address the quality of the waveform matching, several steps were completed to determine the best cutoff point for match quality. The first was a histogram distribution of the match quality values for all the chosen matches (Figure 3). This revealed a bimodal distribution of the 3,315 total matches with large numbers of matches occurring with either relatively low match values (high quality) or high match values (low quality). A match value of 0.33 was observed to be near the middle of these two modes. Next, a visual assessment was done of some matches above and below this threshold, which confirmed that the matches above were often not an accurate assessment of the time-series data while the ones below were accurate. Lastly, many of the matches above 0.33 were duplicates of the same time periods in the data from the higher and lower sets of wavelengths. Therefore, 0.33 was chosen for this data as the cut-off for quality matches to be included; however, this value might not carry over to other river systems. Furthermore, a test was done for any waveform match that was attempting to quantify the same waveform in the data and the worse match was excluded. This is not to say that two matches could not occur at the same time; for instance, a 12 -hr match that sits within a larger 240 -hr match did not require eliminating one, but matches of waveforms with the same actual peak and actual width could not have two different descriptions.

\section{EVALUATING POTENTIAL EFFECTS OF RIVER STAGE, TIDAL PHASE, WIND, AND LOCAL PRECIPITATION ON WAVEFORMS}

To test for the effects of the above factors on 12-hr waveforms, the values for each group were categorized as follows. The upstream river stage was divided into three categories: Low (L), High (H), and Flood (F). The cutoff between $\mathrm{L}$ and $\mathrm{H}$ was the mean stage at RM61 in Clyo,
Georgia, reported by USGS averages over all available years, which is $6 \mathrm{ft}$. The cut-off between $\mathrm{H}$ and $\mathrm{F}$ was the USGS minor flood stage of $11 \mathrm{ft}$, also at RM61. During the study period, water levels were in the L range $64 \%$ of the time, in the $\mathrm{H}$ range $20 \%$ of the time, and in the $\mathrm{F}$ range $16 \%$ of the time. Therefore, this data had lower water levels than average. Tidal range was divided into two groups, neap (N) and spring (S), based on the median value at RM1 during the study period of $7 \mathrm{ft}$. Local precipitation was estimated based on the stage of Ebenezer Creek, divided into Low (L) and High $(\mathrm{H})$ values based on the mean value during the study period of $5.85 \mathrm{ft}$. Wind effect was divided into three categories-Downriver (D), Moderate(M), and Upriver $(\mathrm{U})$-based on the upper and lower quartiles of the vector quantity of wind observed in the $300^{\circ}$ upstream direction. All of these parameters were tested for significance based on a bootstrapped $95 \%$ confidence interval for the mean of the averaged actual wave height.

\section{TOWARD PREDICTIVE MODELING}

Based on the results of the above evaluation for the relative effects of the influencing factors on waveforms, we evaluated the potential to create a predictive model of water level through the study region based on RM1 wave height or storm surge and the river level upstream at RM61. Methods including regression and artificial neural network methods have been considered. Prior work in these areas including the sources cited in this paper have been reviewed and the data available evaluated for suitability for use with these methods. While these methods were not completely implemented in this study, there are ongoing efforts to do so. Toward this effort, a calculation was done of a tidal reach ratio, defined as the ratio of the height of each matched 12-hr wave $\left(\mathrm{H}_{\mathrm{x}}\right)$ to the previous wave height most nearly matched in time and occurring at RM1 $\left(\mathrm{H}_{1}\right)$. RM1 is located near the mouth of the river and is meant to represent a tidal force not impacted by river level. The $\mathrm{H}_{\mathrm{x}} / \mathrm{H}_{1}$ ratio is meant to indicate the amount of that wave that is propagated upstream to various stations, under different conditions.

Improvement of these predictive analyses may be found in cross-correlation of the data produced by all river gauges in the study area. This method does need additional data to be successful, but preliminary analysis (not presented here) is promising. This approach will yield specific temporal relationships to improve and further inform our current spatial data. However, as previously noted, this was beyond the scope of our initial question whether short-term, rapidly deployed, inexpensive temporary river gauges could assess the influence of rainfall flooding, storm surge, and tidal reach on an estuary system. 

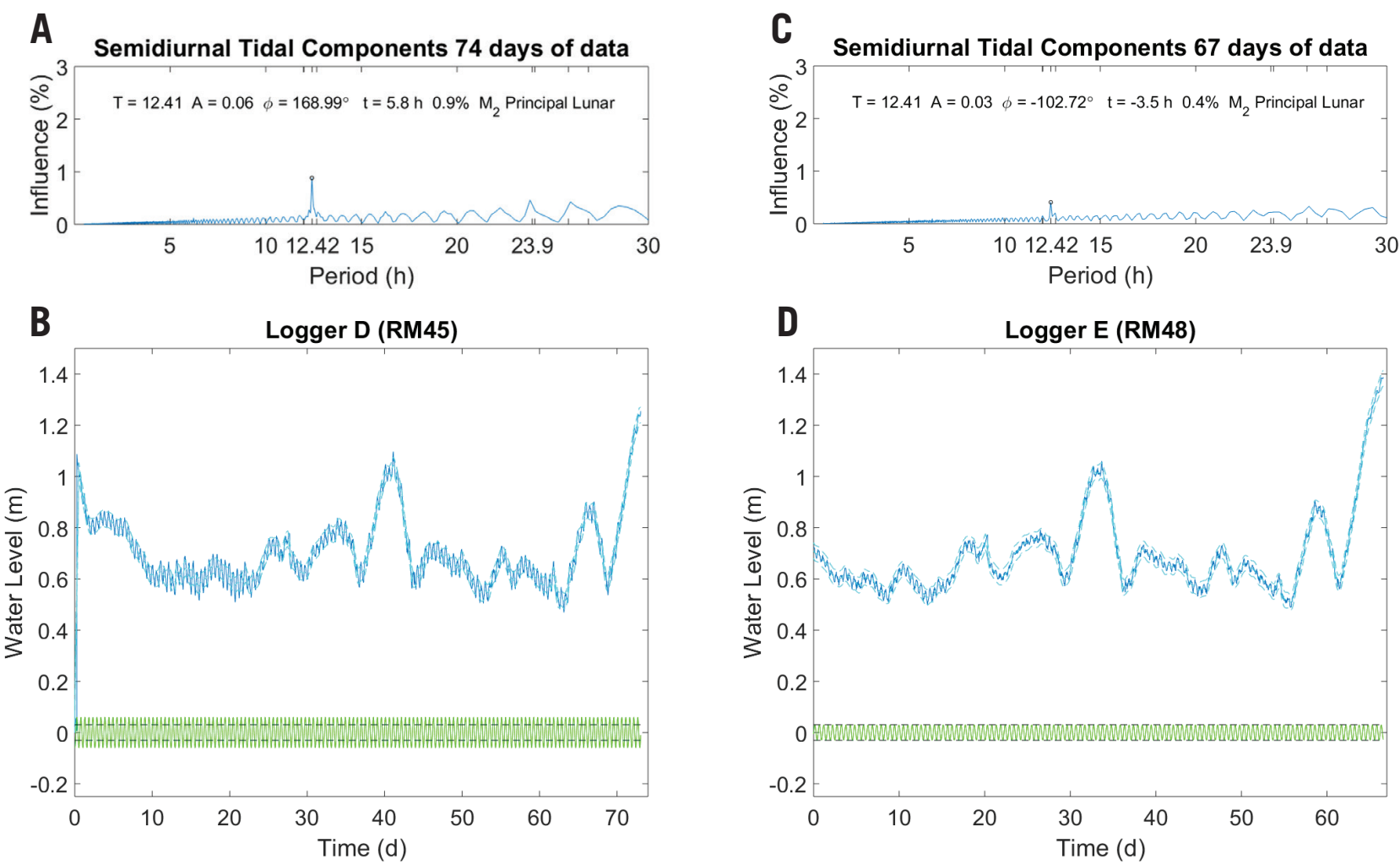

Figure 4. Fourier analysis and quality assurance data for temporary river gauge stations at RM45 Ebenezer Landing and upstream at RM48 just downstream from Berry Landing. (A) RM45 shows clear $12.42 \mathrm{~h}$ tidal harmonics that are 3 standard deviations above the spectral noise. (B) This is corroborated by raw data (solid blue lines) exceeding the 24-h moving average with \pm 0.2 -ft boundaries (dashed light blue lines) and isolated $12.42 \mathrm{~h}$ harmonic amplitude (green waveform) exceeding $0.2 \mathrm{ft}$ wave height (black dashed lines). (C) Although the $12.42 \mathrm{~h}$ tidal harmonic is identified at RM48, it did not exceed our 3-standard-deviation threshold above the noise and only analysis artifacts were isolated. (D) These data are consistent with the raw river gauge data not always exceeding the 24-h moving average $\pm 0.2 \mathrm{ft}$ or the isolated $12.42 \mathrm{~h}$ spectral harmonic amplitude being less than $0.2 \mathrm{ft}$. This suggests the head of tide lies between RM45 and RM48, but more data and further analysis is required to identify the specific location with Fourier analysis.

\section{RESULTS}

\section{DATA OVERVIEW}

Data were collected starting in mid-February of 2018, and data collection is ongoing at the time of publication. For the purposes of this study, data are included up to 8/2/2018. The full time period is available for stations $\mathrm{A}, \mathrm{C}$, and $\mathrm{E}$, in addition to USGS stations 1, 2, 3, and 4. Station B, RM41, is not included due to access issues at high river stage and data quality issues. RM45 had about 20 days of omitted data during this period due to low-quality data but is include otherwise for the entire period. There were two notable highwater events during this period, with one (late May through June) significantly higher than the other (early May). The larger event exceeded the National Weather Service's 11-ft minor flood stage for almost a month and almost exceeded the 15-ft moderate flood stage. There were no storm surge events observed during the study.

\section{FOURIER RESULTS}

Fourier analysis of the river gauge data was confounded by the multiple flooding events experienced during the analysis period. Two specific analyses, identifying a period over 60 days when the river stage was less than $6 \mathrm{ft}$, before the month-long flooding in late May through mid-June when the river stage was over $11 \mathrm{ft}$, isolated a "normal" river stage from an "abnormal" or "flood" stage for Fourier analysis.

Under normal river stage conditions, RM45 at Ebenezer Landing was clearly influenced by the tide with a 12.42$\mathrm{h}$ lunar semidiurnal tidal harmonic in the river stage data. This was confirmed by both the raw data fluctuation about the 24-hr moving average and the isolated $12.42 \mathrm{~h}$ harmonic amplitude exceeding the $0.2 \mathrm{ft}$ head of tide criterion (Figure 4, A and B).

Moving upstream to the next station at RM48, just below Berry Landing, the $12.42 \mathrm{~h} \mathrm{M}_{2}$ harmonic is observed in the river gauge data; however, it does not meet the 3 standard deviation threshold above the noise to be significant. Further, the raw data does not consistently exceed the $0.2 \mathrm{ft}$ height in relation to the 24-h moving average, and the isolated harmonic amplitude is less than $0.2 \mathrm{ft}$ (Figure 4, C and D).

However, the head of tide determination was significantly impacted by the river stage. Considering the month-long flood stage during late May to mid-June, Fourier analysis did not positively identify any tidal influence above RM35 at Purrysburg Landing (Figure 5). 


\section{Supporting Coastal Resiliency by Investigating Tidal Reach and Inter-Connected Factors}
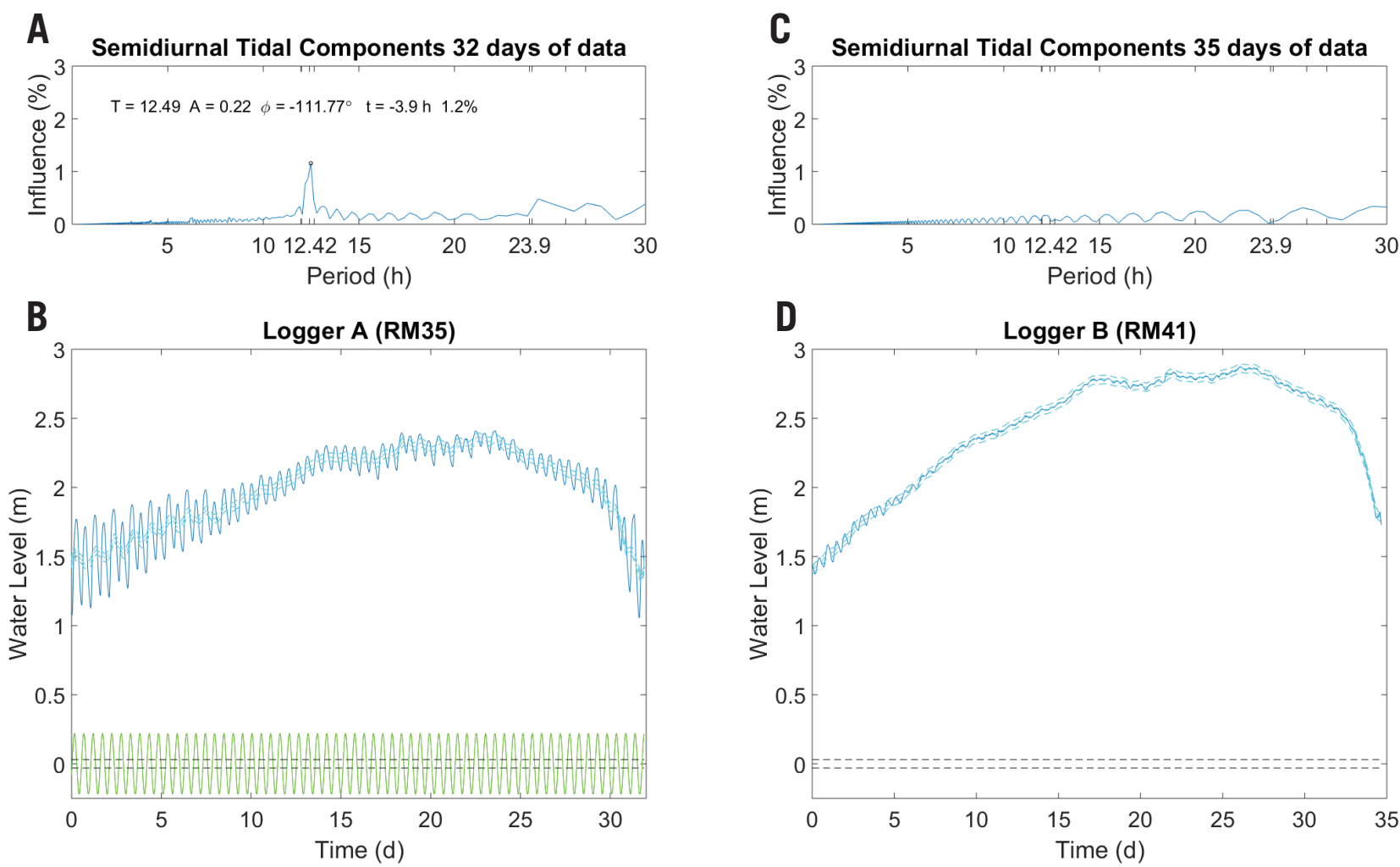

Figure 5. Under flood stage ( $>11 \mathrm{ft}$ ) conditions, head of tide moves downstream. (A) RM35 near Purrysburg Landing shows lunar semidiurnal tidal harmonics that are 3 standard deviations above the spectral noise, even though the limited data has split spectral energy across harmonic periods. (B) The tidal influence is clearly observed in raw data (solid blue lines) exceeding the $24-\mathrm{h}$ moving average with $\pm 0.2 \mathrm{ft}$ boundaries (dashed light blue lines) and isolated $12.42 \mathrm{~h}$ harmonic amplitude (green waveform) exceeding 0.2 feet (black dashed line). (C) No tidal harmonics are observed upriver at RM41 at cut-off \#3 during flood stage. (D) These data are consistent with the raw river gauge data not always exceeding the 24-h moving average $\pm 0.2 \mathrm{ft}$ and nonexistent isolated semi-diurnal harmonic amplitude (absent green waveform). This suggests the head of tide lies between RM35 and RM41 when the river stage is higher than normal, but, as before, more data and further analysis is required to identify the specific location with Fourier analysis.

These data suggest under normal conditions that the head of tide is upriver from Ebenezer Landing but located before reaching Berry Landing between RM45 and RM48. The head of tide moves substantially downriver when it is flooding and is located above RM35 but before RM41. This points to a distinct need to consider river stage when discussing head of tide (Figures 4 and 5). More data would significantly improve this analysis, but these results do demonstrate the relative utility of Fourier analysis in positively identifying tidal influences with a relatively short 30-60 days of data. Moreover, the method of placing inexpensive, rapidly deployed, temporary river gauges could be improved by intermediate analyses and by altering river gauge locations to refine measurements during the determination process. Without significant cost and perhaps in as little as 120 days, the head of tide could be identified to less than 1 river mile if actively analyzed throughout the period instead of leaving all the river gauges in place for the entire time.

\section{MATCH OVERVIEW—WAVEFORM MATCHING}

Table 2 provides all of the high-quality (match value < 0.33 ) matches from the analysis. From RM1 to RM 35 the same total number of 12-hr matches were found, with decreasing average wave height. Below RM35 the only matches were 12$\mathrm{hr}$ and the only other match at RM35 was a 1,200-hr wave period corresponding to the larger upstream-driven flood event. From RM35 to RM48 there were a decreasing number of $12-\mathrm{hr}$ events with decreasing wave height. From RM39 to RM61 both of the noted upstream-driven flood events were matched at each station as were an increasing number of smaller events that were still greater than the 12 -hr wave period.

\section{HEAD OF TIDE-WAVEFORM MATCHING}

Figure 6 provides a summary of the distribution of all the 12-hr waveforms at each station. Of note, there appears to be a trend with two distinct linear or near-linear sections of different slopes. Starting at RM1 there is a decrease of wave height with a gentle slope followed by a breakpoint between RM29 and RM35 and then a rapid decrease to RM48. Also, note that the variability in wave height is highest from RM35 to RM43. Regarding head of tide, RM45 is the last station where the median value is higher than the threshold of 0.2 $\mathrm{ft}, \mathrm{RM} 43$ is the last station where the entire interquartile range is about $0.2 \mathrm{ft}$, and at RM48 even the extreme values are below $0.2 \mathrm{ft}$. Clearly the head of tide exists in this region 
Table 2. A 3-D histogram summary of all the high-quality matches in the analysis from all included stations. Lighter colors (white, yellow) represent fewer matches, while darker colors (blue, black) represent repeated and most likely significant matches. The 12-h wave period is closest to the most influential principal lunar semidiurnal (M2) tidal component.

\begin{tabular}{|c|c|c|c|c|c|c|c|c|c|c|c|c|c|c|c|c|c|c|c|c|c|c|c|c|c|c|c|c|c|c|c|c|}
\hline \multirow{2}{*}{$\begin{array}{r}\text { River Mile } \\
\text { Wave Period } \\
\text { (hours) } \\
\end{array}$} & \multicolumn{5}{|c|}{\begin{tabular}{|l|l|l|l|}
1 & 29 & 27 & 35 \\
\end{tabular}} & \multicolumn{4}{|c|}{39} & \multicolumn{7}{|c|}{43} & \multicolumn{4}{|c|}{45} & \multicolumn{5}{|c|}{48} & & & & 61 & & & River Mile \\
\hline & & $\approx$ & & ป & & $\approx$ & $\stackrel{\sim}{\sim} \underset{\pi}{\infty}$ & \begin{tabular}{l}
$:$ \\
\multirow{8}{*}{} \\
\end{tabular} & $\begin{array}{l}\text { : } \\
\text { స్ }\end{array}$ & . & $\underset{\sim}{\infty}$ & A & \begin{tabular}{l|l|l} 
& & \\
\end{tabular} & 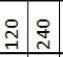 & 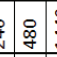 & \begin{tabular}{|l|l}
$g$ \\
$f$
\end{tabular} & 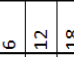 & 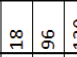 & 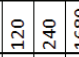 & 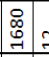 & $\underset{\sim}{\exists} \underset{\sim}{\infty} \stackrel{\infty}{q}$ & $\underset{\infty}{\pi}$ & 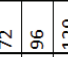 & 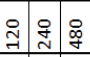 & \begin{tabular}{|l|l|}
\multirow{2}{*}{} \\
\multirow{2}{*}{}
\end{tabular} & & $\underset{-1}{\infty}$ & 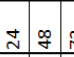 & $\therefore$ & స్తి & 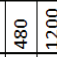 & \begin{tabular}{ll}
\multirow{7}{*}{} & $\begin{array}{l}\text { Wave Period } \\
\text { (hours) }\end{array}$ \\
\end{tabular} \\
\hline $\begin{array}{r}\text { Wave Height } \\
\text { (feet) }\end{array}$ & & & & & & & & & & & & & & & & & & & & & & & & & & & & & & & & $\begin{array}{l}\begin{array}{l}\text { Wave Height } \\
\text { (feet) }\end{array} \\
\end{array}$ \\
\hline $0-0.2$ & & & & & & & & & & & & & & & & & & & & & & & & & & & & & & & & $0-0.2$ \\
\hline $0.2-0.4$ & & & & & & & & & & & & & & & & & & & & & & & 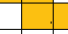 & & & & & 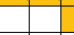 & & & & $0.2-0.4$ \\
\hline $0.4-0.6$ & & & & & & & & & & & & & & & & & & & & & & & & & & & & & & & & $0.4-0.6$ \\
\hline $0.6-0.8$ & & & & & & & & & & & & & & & & & & & & & & & & & & & & & & & & $0.6-0.8$ \\
\hline $\begin{array}{l}0.8-1 \\
\end{array}$ & & & & & & & & & & & & & & & & & & & & & & & & & & & & & & & & $0.8-1$ \\
\hline 1-1.2 & & & & & & & & & & & & & & & & & & & & & & & & 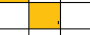 & & & & & & 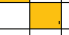 & & $1-1.2$ \\
\hline $1.2-1.4$ & & & & & & & & & & & & & & & & & & & & & & 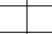 & & & & & & & & & & $1.2-1.4$ \\
\hline 1.4-1.6 & & & & & & & & & & & & & & & & & & & & & & & & & & & & & & & & $1.4-1.6$ \\
\hline $1.6-1.8$ & & & & & & & & & & & & & & & & & & & & & & & & & & & & & & 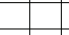 & & $1.6-1.8$ \\
\hline $1.8-2$ & & & & & & & & & & & & & & & & & & & & & & & & & & & & & & & & $1.8-2$ \\
\hline $2-2.2$ & & & & & & & & & & & & & & & & & & & & & & & & & & & & & & & & $2-2.2$ \\
\hline $2.2-2.4$ & & & & & & & & & & & & & & & & & & & & & & & & & & & & & & & & $2.2-2.4$ \\
\hline $2.4-2.6$ & & & & & & & & & & & & & & & & & & & & & & & & & & & & & & & & $2.4-2.6$ \\
\hline $2.6-2.8$ & & & & & & & & & & & & & & & & & & & & & & & & & & & & & & & & $2.6-2.8$ \\
\hline $2.8-3$ & & & & & & & & & & & & & & & & & & & & & & & & & & & & & & & & $2.8-3$ \\
\hline $3-3.2$ & & & & & & & & & & & & & & & & & & & & & & & & & & & & & & & & $3-3.2$ \\
\hline $3.2-3.4$ & & & & & & & & & & & & & & & & & & & & & & & & & & & & & & & & $3.2-3.4$ \\
\hline $3.4-3.6$ & & & & & & & & & & & & & & & & & & & & & & & & & & & & & & & & $3.4-3.6$ \\
\hline $3.6-3.8$ & & & & & & & & & & & & & & & & & & & & & & & & & & & & & & & & $3.6-3.8$ \\
\hline $3.8-4$ & & & & & & & & & & & & & & & & & & & & & & & & & & & & & & & & $3.8-4$ \\
\hline $\begin{array}{l}4-4.2 \\
\end{array}$ & & & & & & & & & & & & & & & & & & & & & & & & & & & & & & & & $4-4.2$ \\
\hline $4.2-4.4$ & & & & & & & & & & & & & & & & & & & & & & & & & & & & & & & & $4.2-4.4$ \\
\hline 4.4-4.6 & & & & & & & & & & & & & & & & & & & & & & 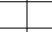 & 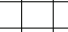 & & & & & & & & & $4.4-4.6$ \\
\hline $4.6-4.8$ & & & & & & & & & & & & & & & & & & & & & & & & & & & & & & & & $4.6-4.8$ \\
\hline $4.8-5$ & & & & & & & & & & & & & & & & & & & & & & & & & & & & & & & & $4.8-5$ \\
\hline $5-5.2$ & & & & & & & & & & & & & & & & & & & & & & & 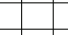 & & & & & & & & & $5-5.2$ \\
\hline $5.2-5.4$ & & & & & & & & & & & & & & & & & & & & & & & & & & & & & & & & $5.2-5.4$ \\
\hline 5.4-5.6 & & & & & & & & & & & & & & & & & & & & & & & & & & & & & & & & 5.4-5.6 \\
\hline $5.6-5.8$ & & & & & & & & & & & & & & & & & & & & & & & & & & & & & & & & $5.6-5.8$ \\
\hline $5.8-6$ & & & & & & & & & & & & & & & & & & & & & & & & & & & & & & & & $5.8-6$ \\
\hline 6-6.2 & & & & & & & & & & & & & & & & & & & & & & & & & & & & & & & & $6-6.2$ \\
\hline $6.2-6.4$ & & & & & & & & & & & & & & & & & & & & & & & & & & & & & & & & $6.2-6.4$ \\
\hline 6.4-6.6 & & & & & & & & & & & & & & & & & & & & & & & 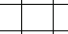 & & & & & & & & & 6.4-6.6 \\
\hline $6.6-6.8$ & & & & & & & & & & & & & & & & & & & & & & & & & & & & & & & & $6.6-6.8$ \\
\hline $\begin{array}{l}6.8-7 \\
\end{array}$ & & & & & & & & & & & & & & & & & & & & & & & & & & & & & & & & $6.8-7$ \\
\hline $7-7.2$ & & & & & & & & & & & & & & & & & & & & & & & & & & & & & & & & $7-7.2$ \\
\hline $7.2-7.4$ & & & & & & & & & & & & & & & & & & & & & & & & & & & & & & & & $7.2-7.4$ \\
\hline $7.4-7.6$ & & & & & & & & & & & & & & & & & & & & & & & & & & & & & & & & 7.4-7.6 \\
\hline $7.6-7.8$ & & & & & & & & & & & & & & & & & & & & & & & & & & & & & 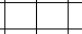 & & & $7.6-7.8$ \\
\hline $7.8-8$ & & & & & & & & & & & & & & & & & & & & & & & & & & & & & & & & $7.8-8$ \\
\hline $8-8.2$ & & & & & & & & & & & & & & & & & & & & & & & & & & & & & & & & $8-8.2$ \\
\hline $8.2-8.4$ & & & & & & & & & & & & & & & & & & & & & & & & & & & & & & & & $8.2-8.4$ \\
\hline $8.4-8.6$ & & & & & & & & & & & & & & & & & & & & & & & & & & & & & & & & $8.4-8.6$ \\
\hline $8.6-8.8$ & & & & & & & & & & & & & & & & & & & & & & & & & & & & & & & & $8.6-8.8$ \\
\hline $\begin{array}{l}8.8-9 \\
\end{array}$ & & & & & & & & & & & & & & & & & & & & & & & & & & & & & & & & $8.8-9$ \\
\hline $\begin{array}{l}9-9.2 \\
\end{array}$ & & & & & & & & & & & & & & & & & & & & & & & & & & & & & & & & $9-9.2$ \\
\hline $9.2-9.4$ & & & & & & & & & & & & & & & & & & & & & & & & & & & & & & & & $9.2-9.4$ \\
\hline $9.4-9.6$ & & & & & & & & & & & & & & & & & & & & & & & & & & & & & & & & 9.4-9.6 \\
\hline $9.6-9.8$ & & & & & & & & & & & & & & & & & & & & & & & & & & & & & & & & $9.6-9.8$ \\
\hline 9.8-10 & & & & & & & & & & & & & & & & & & & & & & L & 17 & & & 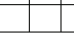 & 1 & 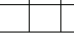 & 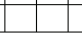 & 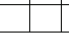 & & $9.8-10$ \\
\hline & & & & Inst & ance & & & $1-5 \operatorname{lns}$ & stance & & & $6-15$ & $\frac{1}{\text { Instanc }}$ & & & & 30 Instanc & & 31-5 & $-50 \operatorname{lns}$ & nstances & & $>501$ & Instances & & & & & & & & \\
\hline
\end{tabular}

but is subject to some variability depending on conditions discussed below.

\section{EFFECTS OF RIVER STAGE, TIDAL PHASE, WIND,} AND LOCAL PRECIPITATION ON WAVEFORMS

Bootstrap confidence intervals for the mean value of wave height revealed that wind and local precipitation were not significant explanatory factors for variability in 12-hr wave height. Further, 95\% confidence intervals overlapped for the various subgroups of data defined by the 3 wind categories and the 2 precipitation categories. However, bootstrap confidence intervals for river stage and tidal phase indicate significance in explaining this variability as confidence intervals for the mean did not overlap. Figure 7 breaks out 12 -hr wave height based on neap or spring tide.
This factor is most powerful in explaining variability in the downstream (below RM35) and upstream (above RM39) regions and less powerful in the middle portion. Regarding head of tide, RM45 is above $0.2 \mathrm{ft}$ for the entire interquartile range during spring tide and below during neap tide.

Figure 8 breaks out 12-hr wave height based on river level. This distinction is powerful in explaining variability throughout, but especially in the middle portion (RM35 to RM39) where the tidal regime distinction is weaker. Note that during "Flood" conditions, head of tide drops down below RM39. There were no 12-hr wave matches observed above RM39. Head of tide moves below RM43 under "High" river condition, but under "Low" conditions it is mostly present at RM45. Based on the interconnectedness of tidal cycle and river level, the 12-hr wave height data are 


\section{Supporting Coastal Resiliency by Investigating Tidal Reach and Inter-Connected Factors}

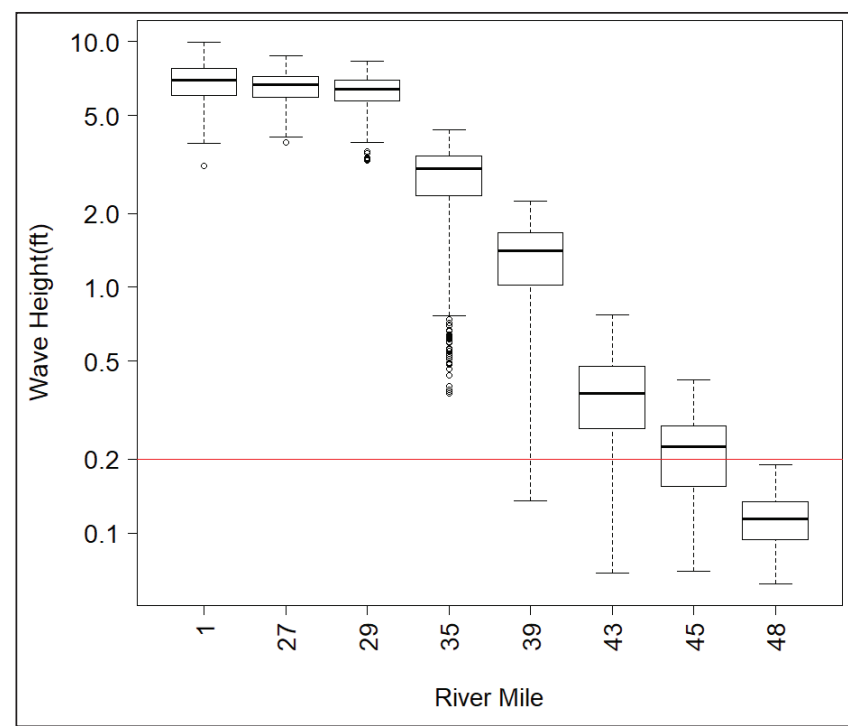

Figure 6. Boxplot of 12-hr waveform height at each station depicting median, interquartile range, and reasonable maximum and minimum values along with the $0.2 \mathrm{ft}$ critical value (red line).

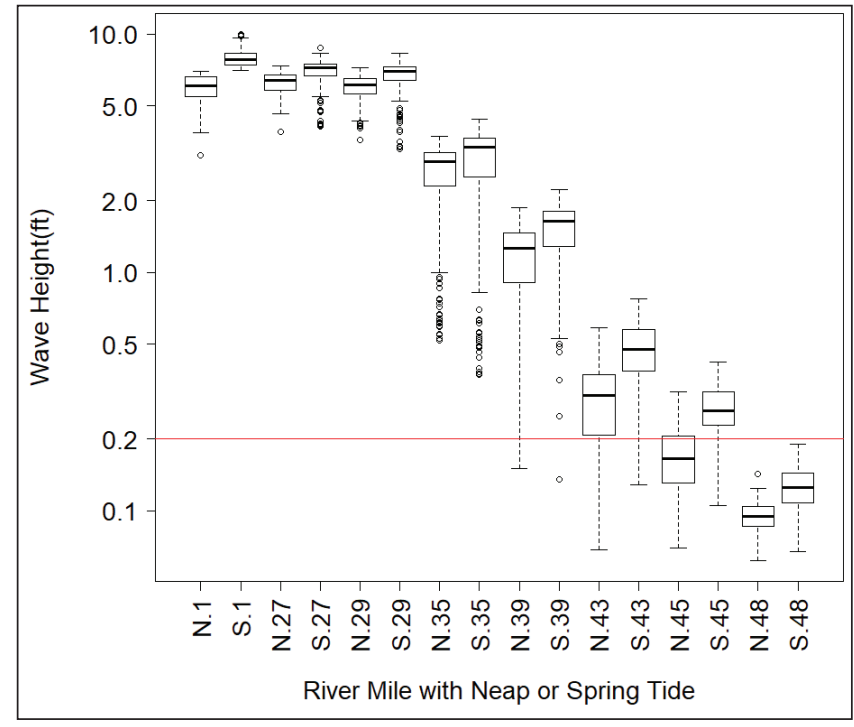

Figure 7. Boxplot of 12-hr waveform height at each station broken out by tidal phase and depicting median, interquartile range, and reasonable maximum and minimum values, along with the $0.2 \mathrm{ft}$ critical value (red line).

shown in Figure 9 with both tidal phase and river level included, allowing a comparison of the relative power of the two variables at the different locations. The data for stations above RM43 are omitted because there is not enough data to adequately subcategorize and because RM48 is entirely below $0.2 \mathrm{ft}$ and thus above head of tide. It is possible to compare the relative power of the two variables at the different locations. The data for stations above RM43 are omitted because there is not enough data to adequately subcategorize and because RM48 is entire below $0.2 \mathrm{ft}$ and thus safely beyond head of tide. While RM45 does have wave heights above $0.2 \mathrm{ft}$ frequently, it is necessary to move down to RM43 to obtain a wave height above $0.2 \mathrm{ft}$ consistently under a wider range of conditions

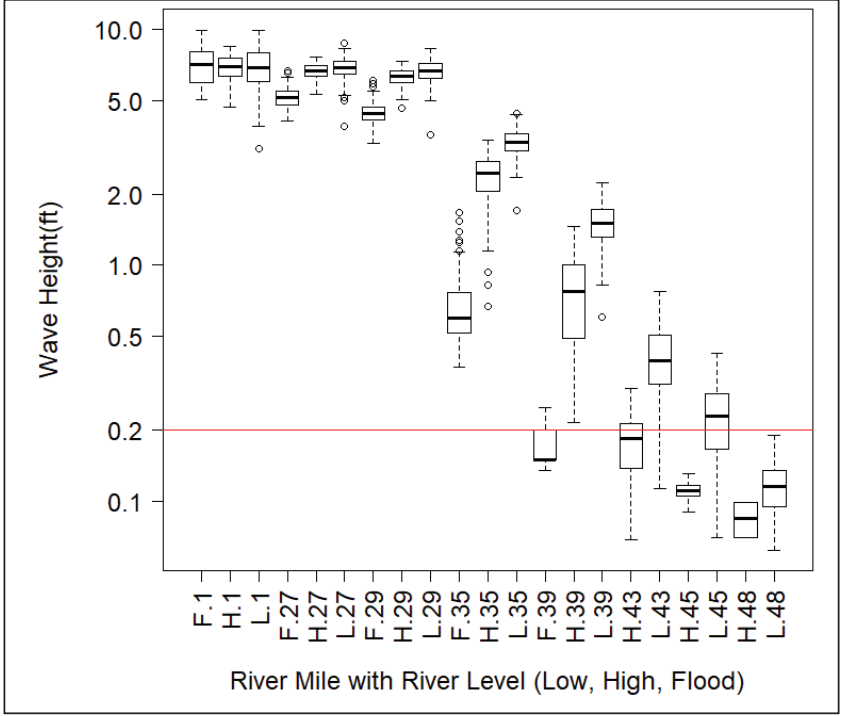

Figure 8. Boxplot of 12-hr waveform height at each station broken out by river level and depicting median, interquartile range, and reasonable maximum and minimum values along with the $0.2 \mathrm{ft}$ critical value (red line).

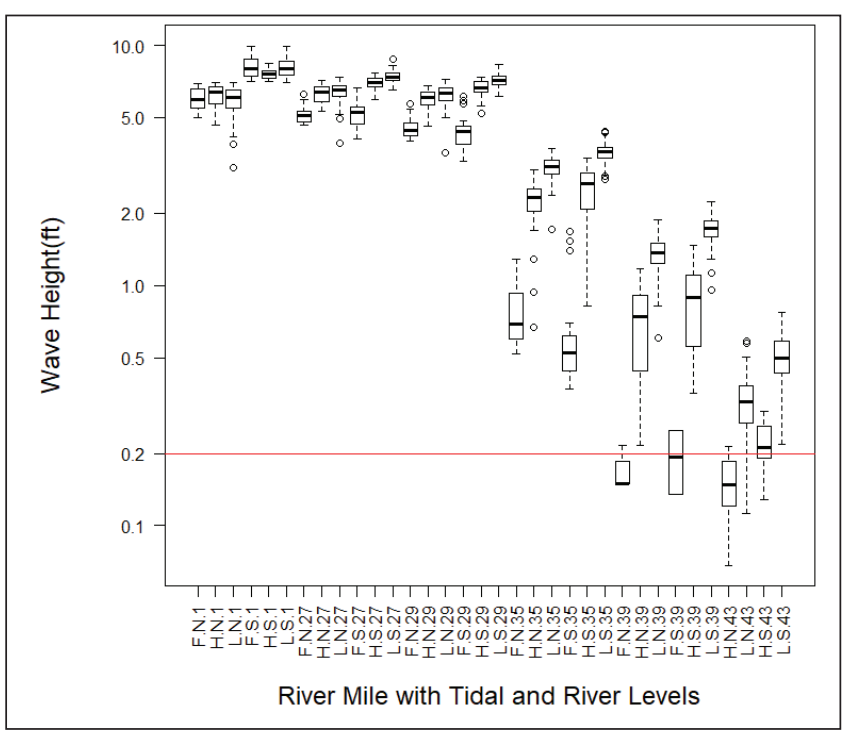

Figure 9. Boxplot of 12-hr waveform height at each station broken out by tidal phase and river level, depicting median, interquartile range, and reasonable maximum, and minimum values along with the $0.2 \mathrm{ft}$ critical value (red line).

including neap tide and some high flows. So, while it is up for some interpretation depending on the way head of tide is defined within the context of these variables and analyses, head of tide likely exists somewhere between RM43 and RM45 on the Savannah River. The range of tidal conditions at RM35 and RM39 is also noteworthy. Under minimal conditions of neap tide and flood flow, the tidal range at RM35 can be as little as $0.5 \mathrm{ft}$, but under ideal conditions of spring tide and low flows it can have a tidal range of over $3 \mathrm{ft}$. Similarly, RM39 can have a tidal range of less than $0.2 \mathrm{ft}$ or almost $2 \mathrm{ft}$, depending on circumstances. 


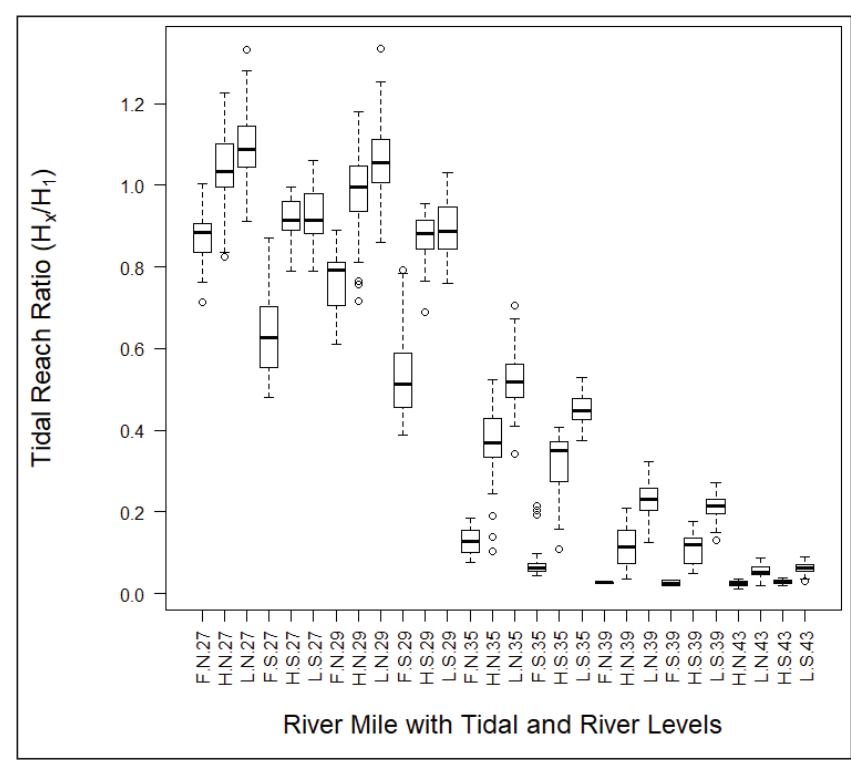

Figure 10. Boxplot of tidal reach ratio broken out by tidal phase and river level, depicting median, interquartile range, and reasonable maximum and minimum values.

\section{INTERPOLATION-WAVEFORM MATCHING}

Linear interpolations between stations yield the following additional results. At low flows and/or spring tides, a median wave height of $0.2 \mathrm{ft}$ probably reaches RM46. Under "Flood" conditions a median wave height of $0.2 \mathrm{ft}$ probably occurs near RM38, with limited effect from tidal cycle.

\section{TOWARD PREDICTIVE MODELING-COMBINED EFFECTS} OF STAGE AND TIDE (STORM TIDE) IN CRITICAL AREAS

A goal of this study was to evaluate the flood risk of areas that might be affected by both storm surges and upriver, precipitation-driven flooding that is not being captured by current SLOSH model predictions. In particular, we would like to be able to predict river levels throughout the study reach based on tidal range, or storm surge, and upriver (RM61) river levels. While the data in this study provided very promising results toward this goal, such a predictive model is not presented here for the following reasons: (1) the study period did not include a storm surge event that could be used to verify the trends seen at lower wave heights at those higher levels and extrapolation would be occurring beyond reasonable limits; and (2) modeling efforts to create robust, validated predictions while verifying that the necessary assumptions for the methods have been met are still under development. Notwithstanding, some results are presented here, specifically the tidal reach ratio (Figure 10). Note that the ratio is only presented from RM27 to RM43 because the ratio at RM1 would be 1 by definition, and the ratio beyond RM43 becomes negligible under all conditions. Also note that as in previous results, "Flood" conditions in the river cause the ratios to be negligible above RM35, at least under the range of 12-hr wave heights observed in this period at RM1.
It is theoretically possible that higher (super-spring) storm tides might create non-negligible ratios farther upstream. Also, based on results presented above, precipitation-driven waves were not observed below RM35. Therefore, based on the range of forcing (tidal and upriver flow) available in this analysis, it is likely that the area most likely to be affected by a combination of storm surge and upstream discharge would be some portion of the river above RM29 and below RM39 (Figure 11). This includes Purrysburg, South Carolina and some of the areas around Hardeeville, South Carolina. On the Georgia side, most of this area is relatively undeveloped as part of the Savannah National Wildlife Refuge (SNWR). Based on a possible worst-case scenario of high water levels in the river and storm tide, it is possible that $40 \%$ or more of the height of this storm surge wave could be propagated this far upstream. These ratios, and/or the predictive modeling of river elevation suggested, could be combined with current SLOSH model results and GIS tools to inform potential inundation areas under predicted conditions. It should also be noted that the impact of elevated water levels in the river has a significant effect on wave propagation all the way down to RM27 and potentially beyond.

\section{DISCUSSION}

\section{RELEVANCE FOR NATURAL RESOURCE MANAGEMENT-HEAD OF TIDE DETERMINATION}

Based on the significant impact of river level, and to a lesser extent, tidal cycle, the Fourier and waveform matching results indicate that a definitive determination of head of tide to a specific river mile based solely on a 0.2 -ft wave height requirement is not possible. Rather, it is necessary to define the tidal conditions and flow conditions that accompany that level. It is also necessary to define how frequently the wave heights must exceed this level under those conditions. For the purposes of this study, we are defining this as the presence of 12-hr waveforms for the majority of the time that river levels are less than the historic mean flow (6 ft in this case) and inclusive of both spring and neap tide, but not storm tides. Based on this definition, both methods of analysis converged on RM45, in agreement with the USDOC information from 1965 and the USACE information from 1994. Interpolation under the waveform matching method may support RM46 under this definition, but with less confidence. Extrapolation of Fourier analysis also suggests RM46. However, this analysis also provided a basis for which GADNR can determine the regulatory head of tide for the purposes of the Protection of Tidewaters Act based on different conditions they feel to be most relevant for this purpose. For instance, the highest upstream extent of 12-hr waveforms of an amplitude of equal to or greater than $0.2 \mathrm{ft}$ occurred anywhere between RM38 and RM46, depending on the tidal cycle and the river level; river level was the dominant factor. In future work, it is likely 


\section{Supporting Coastal Resiliency by Investigating Tidal Reach and Inter-Connected Factors}

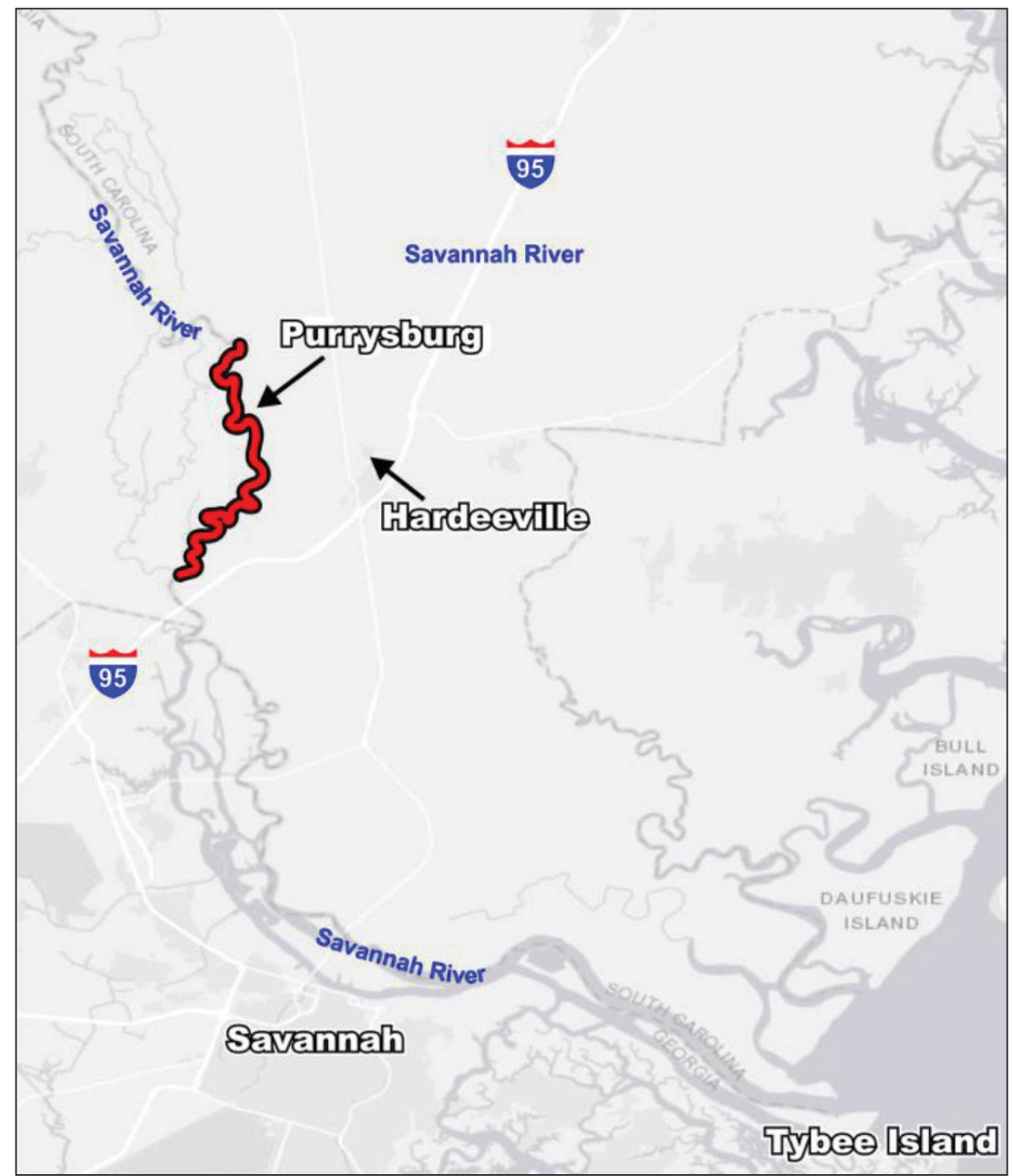

Figure 11. Map of the study area along the Savannah River north of Savannah, Georgia. Highlighted (red) portion of the Savannah River is the region where this analysis of response to tidal upstream flow and rainfall-inundation downstream flooding is most likely to experience synergistic interaction. Note the location west of I-95, which was the edge of evacuations during Hurricanes Matthew and Irma in 2016 and 2017, respectively. This analysis suggests that emergency preparedness professionals may want to consider additional evacuations along low-lying areas of the Savannah River up to RM35 to avoid loss of life during a tropical storm event.

that this method could be equally effective in providing head of tide information for other near-coastal rivers.

\section{RELEVANCE TO SHORT-TERM RESPONSE AND EMERGENCY MANAGEMENT}

Limited resources during life-threatening events require their efficient deployment and use to ensure the most-effective response to protect life and property. This study revealed the need to develop predictive tools to analyze complex hydraulic river systems impacted by multiple deterministic, predictable, and stochastic inputs. However, this study provides some evidence for the potential to model river stage in the nearcoastal region using 12-hr wave heights and Fourier analysis. Moreover, continued use of inexpensive, temporary, rapidly deployed river gauges provides the necessary data to describe hydraulic linkages between fully river-influenced river gauge stations (USGS, Clyo, GA) and tidal stations, but between river-influenced stations (USGS, Abercorn Creek, GA) and fully tidal stations (NOAA, Fort Pulaski, GA) near the mouth of the river.

Literature on the subject and preliminary work with regression models by the authors indicate the strong potential for such a model that may have very accurate prediction capabilities for this region without the need to deploy water level monitoring in this region permanently. The limitation of this approach is lack of a timing component, even if amplitude of the river stage at any given location can be determined. In the future, Fourier analysis and cross-correlation of the combined tidal and river stage data across the region may provide this critical timing of tide wave or storm surge propagation upriver and floodwater downstream. What cannot be overstated, though, is the importance of relating 
all these results to river stage at the time as a highly sensitive factor to river flood and tidal/surge interaction. This study clearly identifies a region of the river between RM35 and just above RM45 that is simultaneously sensitive to both upstream discharge and downstream tidal effects for the local water level. Ultimately, with continued development of these analytical techniques, improving our understanding of the individual contributions of storm surges, tidal influences, and upriver flooding to overall river stage will provide informed decisions on management and development in this section of river potentially impacted more by critical timing rather than solely magnitude of these events. For the future, this region of the river should be developed with care as it may be especially vulnerable to changes in long-term river flow impacted by stochastic precipitation and tropical cyclone events.

\section{RELEVANCE FOR LONG-TERM RESILIENCY AND COASTAL DEVELOPMENT}

An interesting outcome of this study that warrants additional consideration is the observation of a breakpoint location around RM29 where the wave heights started diminishing more quickly moving upstream (Figure 6 and 10). The propagation of these 12-hr waves seems to be impeded in a different way around this region than downstream, potentially by differences in storage or friction. A question for future study is whether that breakpoint depends more on sea level or on local geomorphology. If based on sea level, then perhaps future sea level rise could shift that breakpoint upstream, resulting in significant changes to daily water levels in that upstream area. For instance, the area around Purrysburg, which may now be getting only $40-50 \%$ of the wave height seen at RM1, could start getting $80-90 \%$ of that wave height. However, if based on geomorphology, the breakpoint may be more static, potentially resulting in erosive pressure on the geomorphology. The modeling effort conducted by Tetra Tech in conjunction with the Army Corps of Engineers (2006) indicated that additional floodplain wetlands and bed friction had to be modeled into the system in order to achieve the wave heights observed at RM45. If sea level rise or development affected the behavior of these wetlands, it could alter the head of tide significantly based on their model. Another long-term consideration for resiliency is the proposed reconnecting of the oxbows that were cut off in the latter half of the last century. This potential modification also has the potential to significantly impact the hydrology of this area. Reconnection will likely increase overall bed friction, potentially resulting in less wave propagation upstream or a change in the breakpoint area. It may also allow for more longitudinal dispersion of precipitation-driven waveforms, reducing wave heights of this type in the more downstream area.

\section{ACKNOWLEDGMENTS}

The authors would like to acknowledge the contributions of several organizations for the success of this project. Funding was made possible by the Georgia Sea Grant through its Recovery and Response to Hurricane Irma solicitation. GADNR was a key supporting partner in identifying needs associated with head of tide. Finally, USGS was a critical partner in the Savannah River data available through the Water Data for the Nation program.

The authors thank Captain Shawn Smith of the Savannah State University Marine and Environmental Sciences Department, who was instrumental in installation, maintenance, and data recovery from the temporary river gauges throughout the project period.

\section{REFERENCES}

Flinchem EP, Jay DA. 2000. An introduction to wavelet transform tidal analysis methods. Estuarine, Coastal, and Shelf Science, 51(2):177-200. https://doi.org/10.1006/ ecss.2000.0586.

Jay DA, Flinchem EP. 1997. Interaction of fluctuating river flow with a barotropic tide: a demonstration of wavelet tidal analysis methods. Journal of Geophysical Research, 102(C3):5705-5720. https://doi.org/10.1029/96JC00496.

Jay DA, Leffler K, Diefenderfer HL, Borde AB. 2015. Tidal-fluvial and estuarine processes in the Lower Columbia River: I. along-channel water level variations, Pacific Ocean to Bonneville Dam. Estuaries and Coasts, 38(2):415-433. https://doi.org/10.1007/s12237-014-98190 .

Hale VC, Jackson CR. 2003. Hydrologic modifications to the Lower Savannah River. In: Proceedings of the 2003 Georgia Water Resources Conference. Athens (GA): Georgia Tech.

Hoitink AJF, Jay DA. Jay 2016. Tidal river dynamics: implications for deltas. Rev Geophys. 54(1):240-272. https://doi.org/10.1002/2015RG000507.

Kisi O. 2011. Wavelet regression model as an alternative to neural networks for river stage forecasting. Water Resource Management, 25(2):579-600. https://doi. org/10.1007/s11269-010-9715-8.

Knauss JA. 1997. Introduction to physical oceanography. 2nd ed. Upper Saddle River (NJ): Prentice-Hall, p. 239-244.

Matte P, Jay DA, Zaron ED. 2013. Adaptation of classical tidal harmonic analysis to nonstationary tides, with application to river tides. Journal of Atmospheric and Oceanic Technology, 30:569-589. https://doi.org/10.1175/ JTECH-D-12-00016.1.

Mendelsohn DL, Peene S, Yassuda E, Davie S. 1999. A hydrodynamic model calibration study of the Savannah River Estuary with an examination of factors affecting salinity intrusion, in Estuarine and Coastal Modeling (VI). In: Spaulding ML, Butler L, editors. Proceedings of 


\section{Supporting Coastal Resiliency by Investigating Tidal Reach and Inter-Connected Factors}

the 6th International Conference. Reston (VA): American Society for Civil Engineers, p. 663-685.

Moftakhari HR, Jay DA, Talke SA. 2016. Estimating river discharge using multiple-tide gauges distributed along a channel. J Geophys Res Oceans, 121(4):2078-2097. https:// doi.org/10.1002/2015JC010983.

Moftakhari HR, Jay DA, Talke SA, Kukulka T, Bromirski PD. 2013. A novel approach to flow estimation in tidal rivers. Water Resour Res. 49(8), 4817-4832. https://doi. org/10.1002/wrcr.20363.

NHC. Sea Lake, and Overland Surges from Hurricanes (SLOSH). Miami (FL): NOAA, National Hurricane Center. https://www.nhc.noaa.gov/surge/slosh.php. Rosenquist SE, Moak JW, Green AD, Flite OP III. 2010. Understanding hydrologic variation through time-series analysis. In: Proceedings of the 2010 South Carolina Water Resources Conference. Clemson (SC): Clemson University.

Sassi MG, Hoitink AJF. 2013. River flow controls on tides and tide-mean water level profiles in a tidal freshwater river. J Geophys Res Oceans, 118(9):4139-4151. https:// doi.org/10.1002/jgrc.20297.

Shouke W, Yang H, Song J, Abbaspour K, Xu Z. A waveletneural network hybrid modelling approach for estimating and predicting river monthly flows. Hydrological Sciences Journal, 58(2):374-389. https://doi.org/10.1080/02626667 .2012.754102.

USACE-Savannah District, Tetra Tech. 2006. Development of the hydrodynamic and water quality models for the Savannah Harbor expansion project. Savannah (GA): US Army Corps of Engineers.

USACE-Savannah District. 1994. Draft environmental impact statement: Savannah Harbor long term management strategy study harbor operation and maintenance, Chatham County, Georgia and Jasper County, South Carolina. Savannah (GA): US Army Corps of Engineers.

USDOC. 1965. Hydraulic research in the United States (National Bureau of Standards Miscellaneous Publication 270). Washington (DC): United States Department of Commerce.

Vidakovic B, Mueller, P. 1994. Wavelets for kids: a tutorial introduction. Durham (NC): Institute of Statistics and Decision Sciences, Duke University.

Wolaski E, Andutta FP, Delhez E. 2012. Estuarine hydrology. In: Bengsston L, Herschy RW, Fairbridge RW, editors. Encyclopedia of Lakes and Reservoirs. Dordrecht: Springer. https://doi.org/10.1007/978-1-4020-4410-6_77. 